\title{
Buying insurance in an urn-scheme experiment
}

FRANCIS W. IRWIN and FRANK TOLKMITT, ${ }^{1}$ Department of Psychology, University of Pennsylvania, Philadelphia, Pa. 19104

The Ss drew from urns containing 50, 74, or 99 blue balls and one yellow ball and gained money unless they drew the yellow ball before completing 50 draws. Insurance of zero expected value against the yellow ball was bought increasingly as draws from an um proceeded.

Gradients in various properties of behavior as a function of distance from a goal have long interested students of learning (Hull, 1932), personality (Lewin, 1935), and conflict (Miller, 1944). The present experiment was designed to determine whether Ss who were required to perform a specified number of risky actions in order to gain money would show an upward gradient of buying insurance against these risks as they proceeded through the series. The premiums were such that insurance-buying always had zero expected value. The study was not motivated by interest in problems of commercial insurance and no effort was made to preserve analogies to it.

\section{Subjects}

\section{METHOD}

The Ss were 40 students and secretaries at the University of Pennsylvania, 20 males and 20 females.

Procedure

Each $S$ took part in six procedures. To use one of these for illustration, $S$ was shown a board with 99 blue balls and one yellow ball in numbered holes. The balls were wooden beads $3 / 4$ in. in diameter. They were put into a cylindrical can 5-7/8 in. high and $4-3 / 8 \mathrm{in}$. in diameter and stirred. $S$ was required to draw one ball at a time until he had made 50 draws or had drawn the yellow ball. In the former case $S$ won 500 points worth .1 4 each; in the latter case the procedure stopped and $S$ won nothing. Drawing was without replacement. As $S$ drew the balls, he put them successively in the numbered holes in the board and was thus informed of the number of draws he had made.

Before each block of five draws $S$ was offered insurance, in multiples of 100 points from 0 to 500 , against the occurrence of the yellow ball during that block. Premiums were such that buying insurance had an expected value of 0 , being computed as the product of the amount of insurance and the probability of drawing the yellow ball during the five trials in question, rounded to whole numbers of points. For example, in the case of the 100 -ball urn, 500 points of insurance cost 25 points $(500 \times .05)$ for Draws $1-5$ and 45 points $(500 \times .09)$ for Draws $46-50$. Chips representing points were exchanged between $E$ and $S$ as insurance was bought and as $S$ won or lost in the various procedures. Ss were given 1500 points at the beginning of the experimental session.

The procedure just described was called the 100 Win condition. The 75 Win and 51 Win conditions were identical with this except that they began with the indicated numbers of balls. Conditions 100 Lose, 75 Lose, and 51 Lose differed from the foregoing only in that $\mathrm{S}$ was given 500 points at the start of the procedure and retained or lost it according to whether he did or did not complete 50 draws without drawing the yellow ball. A different random order of conditions was used for each $\mathrm{S}$. The first condition was used for practice only and was repeated as the last condition for purposes of data.

\section{RESULTS AND DISCUSSION}

The urn situation showed no striking departures from statistical expectations. For example, a chi-square test of the 12 subgroups ( 6 conditions by 2 sexes) gave $p>.20$ for differences between observed and expected numbers of occurrences of the yellow ball during Draws 1-25.

No significant differences between the sexes or between the Win and Lose conditions were found. The results were therefore combined over these variables for the purposes of Fig. 1, which shows the mean amount of insurance bought at each of the 10 offers under Conditions 100,75, and 51. The means for Offer 1 are based upon two values for each of $40 \mathrm{Ss}$; later points involve fewer Ss as attrition due to the yellow ball took place. Thus, at Offer 10 there remained 35,27 , and $8 \mathrm{Ss}$ in Groups 100,75 , and 51 , respectively. (The expected numbers were 44,32 , and 9. )

It can be seen that the mean amount of insurance bought increased with fair regularity from initial values of less than 100 points to final values between 300 and 400 points. Conditions 100 and 75 did not differ systematically, but both showed less buying than Condition 51 at each offer. Curves showing the percentage of Ss who bought insurance at each offer were somewhat less regular than those of Fig. 1 but resembled them otherwise. Conditions 100 and 75 rose from 15 to $20 \%$ on Offer 1 to between 70 and $75 \%$ on Offer 10 , crossing each other at 4 points. Condition 51 rose from $25 \%$ to $88 \%$ and lay above the other conditions at all points. Caution must be exercised in interpreting Fig. 1 , since, with only six values of insurance available for choice, no individual S's results for a single condition could rise smoothly from Offer 1 to Offer 10 . Furthermore, no $\mathrm{S}$ used all of these available amounts in a single procedure and some Ss restricted themselves to two or three of the amounts, often 0 and 500. Three Ss bought the same amount (in all cases, 500 points) throughout all offers in all conditions.

It should be noted that the expected value of the game at any point, i.e., 500 points times the probability of avoiding the yellow

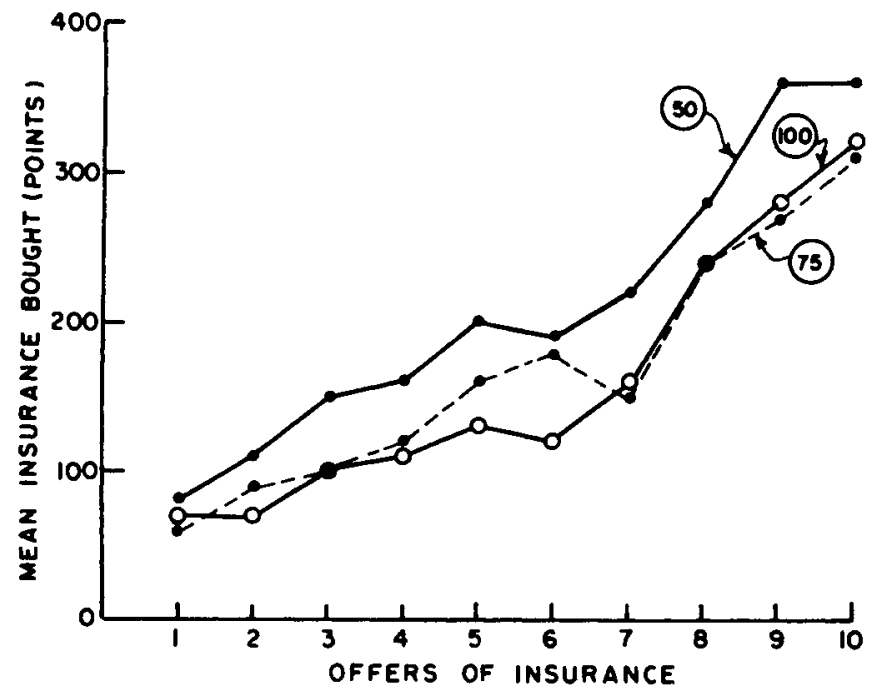

Fig. 1. Mean amount of insurance bought on each of the $\mathbf{1 0}$ successive offers by Ss drawing from urns containing 51,75 , and 100 balls. 
ball on the remaining draws of the 50 , increased as drawing proceded, although $\mathrm{P}(\mathrm{Y})$, the probability of drawing the yellow ball in a block of five draws, also rose. For example, in Condition 100, the expected value rose from 250 points at Offer 1 to 455 at Offer 10; in Condition 75, from 165 to 415 ; and in Condition 51 , from 10 to 85 . Thus, insurance-buying within a condition increased as the expected value increased. Between conditions, however, buying was greatest for Condition 51, which had overall the smallest expected values, the greatest $P(Y)$, and the highest premiums.

Attempts to study effects of the outcome of one procedure upon behavior in the next were impeded by the random appearance of the yellow ball. It can be said, however, that there were no consistent associations between buying insurance during the first three offers and having had the yellow ball come up, or come up late rather than early, in the previous procedure.

It is natural to suppose that insurance-buying reflects a preference for a sure but small loss (the premium) over a large but uncertain loss (or failure to gain). This suggests that the upward gradients of buying were due to the increasing probability of the "catastrophe" of drawing the yellow ball. This factor alone cannot, however, account for the results, since, with $\mathrm{P}(\mathrm{Y})$ (and therefore premiums) constant, insurance-buying was greater, the later the offer in the series. For example, $\mathrm{P}(\mathrm{Y})$ and the premiums were the same for Offers 6-10 in
Condition 100 as in Offers 1-5 in Condition 75, but Fig. 1 shows that more insurance was bought in the former cases. Again, P(Y) was .09, .09 , and .10 at Offer 10 of Condition 100, Offer 5 of Condition 75 , and Offer 1 of Condition 51, respectively, and the premiums were equal or nearly so, but again there was more buying the later the offer. Consequently, in order to account for insurance-buying in these situations it is necessary to take into account S's position between the beginning of a series and the goal of 50 successful draws, as well as the objective probabilities and values at the time of the offer.

\section{REFERENCES}

HULL, C. L. The goal gradient hypothesis and maze learning. Psychological Review, 1932, 39, 25-43.

LEWIN, K. A dynamic theory of personality. New York: McGraw-Hill, 1935. MILLER, N. E. Experimental studies of conflict. In J. McV. Hunt (Ed.), Personality and the behavior disorders. Vol. 1. New York: Ronald Press Co., 1944. Pp. 431-465.

\section{NOTE}

1. This investigation was supported by Research Grant MH-06580 from the National Institute of Mental Health to the University of Pennsylvania. We thank Thomas S. Wallsten and Robert Meltz for various contributions to the study. 